\title{
Vínculos generacionales y experiencias emocionales en el ámbito de una escuela rural albergue
}

Intergenerational bonds and emotional experiences in an rural residential school

Recibido el 25/ 07/ 2020. Revisión del 13/ 09/ 2020. Aceptado 25/09/2020

\author{
Elisa Martina de los Ángeles Sulca \\ elysulca@gmail.com \\ https://orcid.org/0000-0003-0405-0729
}

\section{Consejo Nacional de Investigaciones Científicas y Técnicas (CONICET) \\ Universidad Nacional de Salta (UNSa)}

\begin{abstract}
Resumen
Este artículo analiza las experiencias emocionales que surge de las narrativas de estudiantes indígenas que asisten a una escuela secundaria rural albergue de gestión privada en la provincia de Salta, Argentina. Los datos empíricos se enmarcan en una investigación socioeducativa cuyo propósito es comprender la trama de las experiencias escolares de jóvenes que se autorreconocen al pueblo Tastil. A partir de cuestionarios y entrevistas en profundidad se interpreta los distintos puntos de vista de los(as) estudiantes en relación con las emociones y sentimientos que emergen de los vínculos generacionales en espacio escolar. Los testimonios estudiantiles dan cuenta de que el sentimiento de confianza, inferioridad y vergüenza forman parte de la estructura emotiva que la escuela contribuye a producir e incide en la fabricación de las subjetividades.
\end{abstract}

Palabras claves: experiencias emocionales-vínculos generacionales-escuela rural albergue

\section{Summary}

This article analyzes the emotional experiences that emerge from the narratives of indigenous students attending a rural secondary school, a privately run hostel in the province of Salta, Argentina. The empirical data is framed in a socio-educational investigation whose purpose is to understand the plot of the school experiences of young people that they self-recognition to 
the Tastil town. From questionnaires and in-depth interviews, the different points of view of the students are interpreted in relation to the emotions and feelings that emerge from the generational links in the school space. Student testimonies show that the feeling of trust, inferiority and shame are part of the emotional structure that the school contributes to producing and influences the manufacture of subjectivities.

Keywords: emotional experiences- intergenerational bonds - rural residential school 


\section{Introducción}

Las estructuras sociales y las estructuras emotivas son parte constitutiva de un mismo proceso. Lo cultural-social-histórico no puede ser comprendido con independencia de lo subjetivopsíquico-individual en una configuración social específica. Kaplan (2018) sostiene que el orden social es fundamentalmente de naturaleza afectiva, por ende "ni las emociones pueden ser comprendidas sin tener en cuenta la dimensión estructural de lo social, ni esta última puede ser interpretada si no se pone en juego la producción de la subjetividad” (p. 10).

Esta perspectiva relacional dialéctica permite abordar de manera interdependiente las estructuras sociales y las estructuras emotivas como alternativa a los históricos dualismos objetividad-subjetividad, individuo-sociedad que impidieron el abordaje integral de las realidades sociales.

En el Proceso de Civilización (1987) Elias explica cómo se fue modelando la sociedad occidental desde la Edad Media. El autor pone en el centro del debate sociológico la interdependencia de lo psicogenético y lo sociogenético para argumentar que una configuración social es tal como producto de una configuración emotiva y psíquica determinada. En este sentido, el proceso civilizatorio de Europa Occidental consistió en un progresivo autocontrol de las emociones y la postergación de la satisfacción inmediata de los impulsos. Las necesidades humanas cada vez se ocultan más de la mirada social y se expanden las fronteras de la vergüenza y el pudor constituyéndose en una especie de "aparato de autocontrol automático y ciego que, por medio de una barrera de miedos, trata de evitar las infracciones del comportamiento socialmente aceptado." (Elias, 1987, p. 452).

Estas herramientas teóricas permiten comprender la urdimbre social de las emociones y sentimientos que la escuela contribuye a producir. Las relaciones de intersubjetividad que se construyen en el cotidiano de esta institución generan una red de sentimientos (Kaplan, 2018) que enaltecen o inferiorizan a los sujetos y que inciden en la producción de imágenes y autoimágenes escolares y sociales (Kaplan, 2008).

En este artículo se presenta un análisis de las experiencias emocionales que emergen de las interacciones escolares y que dejan huellas en las biografías estudiantiles. Los datos empíricos surgen de un estudio de carácter socioeducativo cuyo propósito fue comprender las experiencias escolares de jóvenes que se autorreconocen al pueblo indígena Tastil, que se 
escolarizan en una institución secundaria ${ }^{1}$ rural albergue de gestión privada ${ }^{2}$ ubicada en la provincia de Salta, al norte de Argentina.

\section{Método}

Se planteó una investigación cualitativa de carácter exploratoria acorde a la naturaleza del objeto de estudio, en tanto su buscó acceder a los puntos de vista (Bourdieu, 2013) de los(as) estudiantes acerca las experiencias que construyen en la escuela rural albergue.

Las herramientas utilizadas para la recolección de datos fueron el cuestionario y la entrevista en profundidad. La primera permitió caracterizar a la población en estudio a modo de una fotografía de realidad (Gallart, 1993) para posteriormente profundizar la información mediante las entrevistas en profundidad (Piovani, 2007). Las dimensiones indagadas fueron las relaciones generacionales e intergeneracionales, las normas y reglamentos escolares, los sentidos de pertenencia a la escuela, las imágenes y autoimágenes acerca de sí mismos y de los otros y las emociones y sentimientos de la vida escolar.

La muestra estuvo constituida por dieciséis jóvenes que se autorreconocen al pueblo Tastil y provienen de la comunidad Las Cuevas, el grupo mixto cursa de primero a quinto año del nivel secundario. Vale destacar que a la institución escolar asisten jóvenes de otras comunidades. Sin embargo, el grupo seleccionado es mayoritario dentro de la institución, permanecen de lunes a viernes y los fines de semana regresan a sus hogares. Esta particularidad permitió contactarlos en la escuela y fuera de ella (en el regreso a sus hogares y en la comunidad de origen).

${ }^{1}$ La estructura del Sistema Educativo argentino está conformada por cuatro niveles: inicial, primaria, secundaria y superior. En el año 2006, mediante la aprobación de la Ley de Educación Nacional 26.206, se establece la obligatoriedad del nivel secundario con duración de 5 (cinco) o 6 (seis) años según lo defina cada provincia del país. En la provincia de Salta la duración del nivel secundario es de 5 (cinco) años.

${ }^{2}$ La Ley de Educación Nacional 26.206, en el Art. 14. Cap. I. describe al Sistema Educativo Nacional como un conjunto organizado de servicios y acciones educativas reguladas por el Estado que posibilitan el ejercicio del derecho a la educación. Lo integran servicios educativos de gestión estatal y privada, gestión cooperativa y gestión social de todas las jurisdicciones del país, que abarcan los distintos niveles, ciclos y modalidades de la educación. 
Los datos recogidos fueron analizados e interpretados de manera procesual a lo largo de la investigación (Valles, 1999). Con el programa informático Atlas.ti se procedió a la agrupación de los referentes empíricos según categorías precedentes, surgidas del marco teórico y el estado del arte, y categorías emergentes, producto del material empírico.

\section{Resultados}

El análisis de las narrativas estudiantiles permitió identificar algunas de las múltiples dimensiones que urden las experiencias escolares de los(as) jóvenes indígenas. Siguiendo a Dubet y Martuccelli (1998) se comprende a la experiencia escolar como una construcción relacional intersubjetiva en la que se combinan, articulan y fusionan múltiples dimensiones que se singularizan según cada sujeto. Una de las dimensiones identificadas es la experiencia emocional como producto de los vínculos que se construyen en la trama escolar.

\section{Muros simbólicos y sociabilidad escolar}

Cohabitar con otros/as (Kaplan, 2016) en un espacio-tiempo regulado por normas específicas como en la escuela genera tensiones entre la personalidad individual y la personalidad colectiva (Simmel, 2003; Kaplan, 2016, 2018). Las relaciones nosotros-otros, yo-ellos que se construyen en las interacciones cotidianas trae aparejado conflictividades latentes que se comprenden si ponemos en el foco en la convivencia escolar.

Sentirse excluido o incluido, respetado o menospreciado (Kaplan y Silva, 2018), valorado o inferiorizado forman parte de modos de sociabilidad escolar que dejan huellas en la subjetividad e inciden en la producción de la valía social y escolar (Kaplan, 2008).

Los(as) estudiantes indígenas permanecen albergados en la escuela de lunes a viernes. En este marco comparten la rutina doméstica de comer, dormir, higienizarse, realizar actividades de recreación que junto con lo propiamente escolar constituyen una trama compleja.

Las narrativas estudiantiles aluden a vínculos de amistad, compañerismo y confianza, pero también mencionan la contracara de estos vínculos. En términos de Silva (2018) hay modos de relacionamiento simétrico y asimétrico, el primero caracterizado por el reconocimiento positivo del otro y el segundo como la negación de su existencia. La separación entre un nosotros (que se constituye a partir de que sus miembros comparten ciertos gustos, códigos, etc.) y un ellos (con los que no tienen las mismas afinidades) funcionan como fronteras entre grupos.

Contacto: revistaeduca@umch.edu.pe_ISSN : 2617-0337 revistas.umch.edu.pe/ 
"No me junto con ellos", "no le doy lugar", "le paré la mano", "mantengo distancia" son algunas manifestaciones de los(as) estudiantes que dan cuenta de los muros simbólicos que se construyen en la sociabilidad escolar. Kaplan (2013) señala que esta tendencia a la evitación o incluso a la eliminación del otro por considerarlo amenazante es una construcción cultural que opera de modo natural en la disociación entre grupos y genera sentimientos de exclusión. No sentirse parte, emerge de dos facetas constitutivas de la exclusión: la material-objetiva y la simbólico-subjetiva. Es decir, estar objetivamente excluido y, a la par, sentirse excluido (Kaplan, 2008) en un marco de interacciones donde un individuo o grupo posee cierto poder para generar ese sentimiento en el otro.

En el clásico Ensayo acerca de las relaciones entre establecidos y forasteros (2003) Elias describe los mecanismos simbólicos mediante los cuales los establecidos-incluidos en posiciones de poder estigmatizan a los forasteros-excluidos. Si bien ambos grupos comparten nacionalidad, clase social y etnia hay una percepción y autopercepción acerca de sí mismo y de los otros basados en el valor y el disvalor humano. Quienes ostentan el poder por percibirse humanamente superiores despliegan estrategias que interpelan subjetivamente la valía social del grupo de menor poder, quienes terminan por asumir, al menos por un tiempo, la inferioridad atribuida. Este estudio empírico a pequeña escala desarrollado en la comunidad de Winston Parva constituye un marco fundamental para abordar la sociodinámica del poder entre individuos y grupos en la escuela.

Algunos testimonios estudiantiles expresan lo siguiente:

Cuando entré al colegio había dos chicos que se habían quedado de curso, lo primero que hicieron fue acercarse a mí y a otro compañero y decirnos que aquí no se buchonea nada, el que buchonea es boleta y se reían.

\section{$\mathbf{E}^{3}$ : ¿Qué hiciste ante esa situación?}

Nada, ellos son más grandes, conocen bien el colegio, como es la movida aquí adentro y por ahí lo hacían por eso, pero no quise decir nada porque ahora que los conozco más son así, ningunean a cualquiera.

(Estudiante varón de 2do año)

Los recién llegados, como lo expresa Elias (2003) para el caso de los forasteros, desconocen "la movida" del espacio escolar, mientras que los más antiguos tienen ciertas normas creadas

\footnotetext{
${ }^{3} \mathrm{E}$ : refiere a entrevistadora.
}

Contacto: revistaeduca@umch.edu.pe_ISSN : 2617-0337 revistas.umch.edu.pe/ 
por ellos mismos como "no buchonear nada" que es impuesta a los que recién ingresan. Al igual que en Winston Parva, la antigüedad en el lugar, la organización grupal, el cumplimiento de las normas compartidas hace que los establecidos se consideren a sí mismos como superiores respecto de los forasteros. Surge la hipótesis de que el rechazo hacia quienes no comparten ciertas pautas, o desconocen las reglas creadas por el grupo de mayor poder, son la base para afirmar las cualidades distintivas de superioridad y reforzar la identidad grupal de los más poderosos.

Los establecidos para mantener una relación de poder despliegan dos estrategias: la cohesión grupal y el cierre de filas. La primera tiene lugar a partir de "la conformidad con las normas grupales. La sanción por la desviación grupal, en ocasiones incluso por la sospecha de desviación, es la pérdida de poder y la erosión del estatus personal” (Elias, 2003, p. 241). Para conservar dicha posición evitan el contacto con los forasteros, "cierran filas por miedo a la contaminación" (p. 227) de allí que quien se acerque a los forasteros "corre el riesgo de perder el aprecio de sus miembros, es decir, puede dejar de compartir los valores humanos superiores que los establecidos se atribuyen a sí mismos" (p. 227).

Las relaciones de poder entre grupos escolares se manifiestan, en muchos casos, mediante la evitación, la burla y la humillación que se expresan de manera cotidiana y naturalizada, casi como del orden lúdico (Silva, 2018):

Aquí nos hacemos chistes, nos cargamos todo el tiempo, jugamos más que nada. Nos reímos. Cada uno se manda sus cosas y es así porque nos conocemos bien, vivimos juntos y bueno nos tenemos esa confianza.

\section{E: ¿Qué tipo de chistes se hacen?}

De todo tipo. Por ejemplo, el otro día Saúl le dijo a Juan, Dumbo. El otro se cortó el pelo muy corto y como tiene tremendas orejas le puso ese apodo, pero no pasa nada, todos nos reíamos.

(Estudiante mujer de 1er año)

No obstante, cuando las bromas o chistes trastocan los sentimientos dejan de ser tal. El límite es subjetivo en tanto se "hiere los sentimientos" del/a otro/a. Es ahí donde se encuentra la diferencia entre el dolor físico y el dolor simbólico, producto de un tipo de violencia.

La frontera entre lo que produce diversión y los que produce dolor se vuelve porosa y para no trascenderla es necesario tener "tacto", "saber hasta dónde llegar": 
Hay un chico del otro curso que me decía negro, después carbón y un día me dijo morcilla y no, ahí dije o lo pongo en su lugar o va a seguir con eso.

\section{E: ¿Lo pones en su lugar?}

Sí, lo hablé bien, en serio, mirándolo a los ojos para que entienda que le hablo en serio, pero no entendió y tuve que pegarle.

\section{E: ¿Te sentiste discriminado con lo que te dijo?}

Sí, es discriminación, pero él cree que es broma, que es un chiste y te lo dice como si nada, no tiene ni tacto. Algunos se ríen, pero no está bien que diga eso, no sabe si hiere los sentimientos de la otra persona.

\section{E: ¿Por qué decís que discriminar es herir los sentimientos?}

Claro, cuando uno pega lastima el cuerpo y duele. Ahora cuando se dicen cosas malas o con mala intención no se lastima el cuerpo, lastimas a los sentimientos, duele.

(Estudiante varón de 4to año)

El límite entre lo que se considera un juego y aquello que no lo es se vuelve impreciso. "Joder" y "jugar a molestarse" se presentan como modos de sociabilidad que tienen un "papel decisivo en la constitución de identidad, la regulación de las emociones y los modos de construcción de aceptación o rechazo de ciertas diferencias sociales” (Paulín, 2013, p. 194).

En otros casos las relaciones de poder entre grupos se expresan de manera más explícita. "No hay trato", "es una cuestión de piel", son algunas expresiones que dan cuenta de relacionamientos asimétricos:

Hay de todo en el colegio, compañeros que son buenos, respetuosos, tranquilos y otros que... no sé cómo explicarte, pero son zarpados, mezquinos, no te prestan cosas, ni las tareas. Hacen su vida, se preocupan por ellos y por nadie más (...) cero compañerismo.

\section{E: ¿Por qué crees que tienen esas actitudes?}

No sé por qué tienen esas actitudes, porque nunca le hicimos nada. Una vez no copié la tarea que dictaron y tampoco mis compañeros, entonces le pedimos a las chicas de adelante que siempre tienen todo y no quisieron, no nos pasaron (...) y bueno tachadas para todo el viaje.

(Estudiante varón de 4to año)

"Ser mezquino", "hablar a las espaldas", "mandarse al frente" marcan una distancia que se mantiene como un principio de reciprocidad, trato como soy tratado/a. Estas prácticas fabrican una barrera entre estudiantes o grupos que sostienen que será difícil derribar, "se tachan para 
todo el viaje" y en algunos casos queda latente el desencadenamiento de la violencia física, ya que cuando las actitudes "sobradoras", "de mala onda" e "individualistas" alcanzan el límite de la tolerancia dan lugar a prácticas de violencia física:

(...) las chicas, se tiran de los pelos, algunas se empujan, se pegan, pero hasta ahí no más, es como para quitarse las ganas.

\section{E: ¿Para quitarse las ganas?}

Es una forma de decir (...) a veces vienen buscándose y se insultan hasta que encuentran el momento y se agarran ahí.

(Estudiante mujer de 5to año)

Los atributos sobre los que recae la discriminación o inferiorización es el cuerpo tratado socialmente (Bourdieu, 1999), el color de piel y el origen sociocultural:

(...) los que vienen de afuera que a veces te hacen sentir que sos como raro (...) te empiezan a preguntar cómo vivís porque piensan que vivimos en choza.

(Estudiante mujer de 3er año)

La mirada externa despectiva genera percepciones negativas, "te hacen sentir que sos raro", "te hacen sentir de menos", estos sentimientos de inferioridad que relatan los(as) estudiantes dan cuenta del estigma de la identidad indígena que prevalece en los discursos cotidianos. A su vez, el hecho de que "piensen que vivimos en choza", tal como testimonia la estudiante, pone en evidencia la vigencia de un imaginario esencialista que cristaliza la cultura de estos grupos al quitarle su agenciamiento histórico.

Ciertas prácticas y discursos, sin ser conscientes, inciden negativamente en la subjetividad y dan lugar a sentimientos de vergüenza:

(...) cuando empiezan a mirarte mucho o por ahí dicen indios con una intención mala, te hace sentir de menos, me da vergüenza, no es lindo.

(Estudiante mujer de 3er año)

La vergüenza como dolor social (Goffman, 2009) genera sentimientos de inferioridad, "te hace sentir de menos" tal como narra la estudiante. Sentir vergüenza emana del juego de miradas y de las percepciones de tales miradas. Retomando a Le Breton (2010), la mirada sobre y hacia el otro está imbricada en una trama simbólica por cuanto reviste de significados a la vez que es significada. Kaplan (2013) argumenta que "en esta dinámica de desciframiento de imágenes y autoimágenes se tensiona el par superioridad-inferioridad" (p. 56). 
En las interacciones entre pares también subyace un trato peyorativo ligado a la pertenencia del pueblo Tastil que marca la diferencia entre un nosotros criollos y un ellos indígenas:

A veces nos dicen tastileño (en referencia a sus compañeros/as) pero con mala onda o como burlándose porque algunos de ellos dicen que no son indios (...) porque se reconocen criollos.

(Estudiante mujer de 3er año)

La diferenciación entre indígenas y criollos está basada en sentimientos de superioridad humana como lo sostiene Elias para el caso de los establecidos y forasteros, en tanto las comunidades rurales de las que provienen los(as) estudiantes de dicha institución comparten características socioeconómicas y socioculturales. No obstante, estas diferenciaciones tienen una raigambre histórica que "lejos de haberse congelado de una vez y para siempre, se han ido resignificando en y a través de relaciones sociales y contextos históricos cambiantes" (Briones, 2004, p. 72) y que no necesariamente se asientan sobre elementos explícitos, sino más bien en lo simbólico subjetivo, en el sentimiento de superioridad e inferioridad.

Los testimonios de los(as) jóvenes entrevistados expresan la complejidad de cohabitar con otros, los vínculos que generan y cómo a partir de ello "construyen sus referencias identitarias y se subjetivan” (Paulín et al, 2015, p. 241). Así también, los sentidos de pertenencia a la escuela de los cerros, como la denominan dada su ubicación socio-geográfica, están atravesados por sentimientos de superioridad e inferioridad.

\section{Sentidos en torno a la escuela rural albergue}

Sentirse parte (o no) de la escuela, según los testimonios estudiantiles, está ligada a tres aspectos. En primer lugar, los lazos socio-afectivos que construyen con pares y docentes lleva a que se identifiquen con la misma y depositen confianza en ella. En segundo lugar, lo que les ofrece la escuela en términos materiales y simbólicos incide en su valoración positiva. Por último, los sentimientos de inferioridad ligados a la ubicación sociogeográfica de la escuela entra en contradicción con las creencias de superioridad relacionada a la educación privada que imparte la misma.

Una estudiante expresa: 
Siento orgullo de mis amigas, siento orgullo de estudiar en esta escuela porque aquí tengo amigas que son como mis hermanas. Eso es lo que más me gusta del colegio y lo digo siempre.

(Estudiante mujer de 3er año)

La escuela secundaria posibilita modos de sociabilidad que en la comunidad de pertenencia no es posible, o al menos no de la misma manera, ya que asumen compromisos con las tareas de hogar o bien salen en la búsqueda de ingresos económicos. De allí que encontrarse con otros/as más o menos semejantes en un espacio-tiempo compartido es valorado:

El colegio me gusta más que mi casa (...) cuando vengo aquí me junto con mis amigas, jugamos cuando podemos o charlamos, cosa que en mi casa no hago porque vivo lejos de todos y no tengo esta vida, tampoco tengo tiempo para salir porque me quedo a ayudar a mi mamá a cuidar a las ovejas los fines de semana.

(Estudiante mujer de 5to año)

Diversos autores (Pérez y Castro Pozo, 2008; Gonzáles Cangas, 2006; Cárdenas, 2002) manifiestan que la escuela secundaria, sobre todo en las comunidades rurales, constituye un espacio de sociabilidad juvenil. Allí los sujetos adquieren un estilo y un estatus al pasar un tiempo de su vida generando vínculos, interactuando con pares más o menos semejantes que comparten intereses y proyectos en el marco de una acción concreta: la escolar.

También los bienes materiales y simbólicos que ofrece la escuela, llevan a que se sientan parte de ese espacio, así relata un estudiante:

Al principio no quería venir a este colegio. No quería ser de aquí, mi mamá fue la que me mandó, pero con el tiempo me hice de amigos, conocí a algunos profes muy buenos y eso me hizo recapacitar y valorar al colegio. Nos ofrece mucho, comida, techo, nos enseñan, nos cuidan.

(Estudiante varón de 2do año)

Vale destacar que es la única institución de nivel secundario en la zona y por ende la más cercana a sus hogares. Cuando se indagó acerca de los motivos de elección los(as) jóvenes señalan que sus padres los enviaron a estudiar allí en tanto no les resulta un gasto económico que no podrían solventar y, además, por la cercanía a sus hogares, ya que, si bien permanecen en el albergue de lunes a viernes, los fines de semana regresan con sus familias y participan del conjunto de actividades del hogar y otras que generan ingresos. 
No obstante, en otros relatos la ubicación socio-geográfica de la escuela aparece como una desventaja y genera sentimientos de inferioridad (Gualejac, 2008). Los cuidados que reciben por parte de docentes y otros actores de la institución son percibidos como una sobreprotección que los hace sentir de menos:

Yo siento que nos cuidan mucho aquí (...) siempre nos dicen que venimos de medio de los cerros y te ven así, como que no sabemos nada (...) siento que es como que nos tienen lástima por venir de medio de los cerros, que no sabes nada y por eso te enseñan así, poco...

(Estudiante mujer de 4to año)

Estas percepciones en torno a la escuela generarán vínculos de "baja intensidad" (Kessler, 2004, p. 194) con la misma, ya que "venir de los cerros" y sentirse tratados como "pobrecitos" genera ciertas actitudes de "lástima” y "sobreprotección" que los(as) estudiantes califican como negativas en la medida en que inciden en la enseñanza y en las relaciones pedagógicas:

Algunas veces siento que nos dan cosas fáciles o que ya sabemos porque creen que no vamos a poder, (...) o nos cuidan mucho porque somos del cerro, o sea no dejan que aprendamos solos. En todo momento están ellos para decirnos que nos bañemos, que limpiemos, que comamos y eso no sé (...) yo pienso que no vamos a aprender nada porque ellos no nos dejan, dicen todo lo que tenemos que hacer todo el tiempo (...) es como que somos pobrecitos, no de pobres, sino de que no sabemos, no podemos, de eso ¿entendés?

(Estudiante mujer de 4to año)

La tensión entre el lugar de procedencia y el modo en que se estructuran los vínculos pedagógicos dan lugar a operaciones de clasificación que reproducen una estructura social que no siempre es consciente. Kaplan (2008) sostiene que las formas escolares de clasificación son instrumentos de conocimiento, pero que cumplen funciones que no son de puro conocimiento, es decir, son trasmitidas en y mediante las prácticas fuera de toda intención propiamente pedagógica.

En Las categorías del juicio profesoral (1988) Bourdieu y Saint Martin exponen que los juicios que emiten los profesores sobre sus estudiantes están ligadas a dos dimensiones entrelazadas: el origen social y las calificaciones obtenidas. 
Los calificativos más favorables aparecen cada vez con más frecuencia a medida que el origen social de los alumnos es más elevado (...) Se ve que los considerandos del juicio parecen más frecuentemente ligados al origen social que la calificación por medio de la que se expresan: esto, sin duda, porque revelan más directamente la representación que el profesor se hace de los alumnos partiendo del conocimiento que tiene, por otra parte, de su hábito corpóreo (hexis) y de la evaluación que de él se hace en función de criterios completamente ajenos a los que están explícitamente reconocidos en la definición técnica del desempeño exigido. (Bourdieu y Saint Martin, 1998, p. 7).

Entre los hallazgos de la investigación los autores destacan que los calificativos que realizan los profesores sobre los estudiantes varían de acuerdo al origen social, cuanto más elevando es este, más favorables son, por contraste cuando el origen social es más bajo, las apreciaciones son más severas. Además, las notas promedio suben a medida que se asciende en la jerarquía social, lo que deja en evidencia que el origen social se antepone a las calificaciones de los estudiantes en la emisión de juicios.

Los discursos estudiantiles, acerca de sus percepciones sobre las prácticas de enseñanza, expresan los eufemismos imperantes sobre origen y destino como inexorables. Kaplan (2008) señala que "en las prácticas educativas es habitual encontrar una argumentación sobre la desigualdad educativa que responsabiliza al individuo de su propio éxito o fracaso" (p. 17) y que se afirma en el origen social y cultural de los(as) estudiantes y que Bourdieu (1978) ha denominado racismo de la inteligencia. A través de las prácticas de enseñanza los(as) estudiantes se perciben a sí mismos como inferiores, en tanto sus posibilidades de aprender tienen un límite.

Sin embargo, cuando se ahonda en los relatos, subyacen representaciones positivas ligadas al carácter privado de la institución que deja de lado la ubicación socio-geográfica:

(...) para mí está bien que sea privado eso lo hace como más importante o no sé.

\section{E: ¿Por qué decís que colegio privado es más importante que un colegio público?}

Yo creo que sí, no cualquiera va a un colegio privado o sea aquí no pagamos nada, en los colegios de Salta sí, esos se pagan y bueno no es lo mismo decir que venís de un colegio privado que de un colegio público.

(Estudiante varón de 3er año) 
Estos distintos puntos de vista, que subyacen incluso de un mismo actor no pueden ser explicados por separado, sino que "hay que confrontarlos como ocurre en la realidad, no para relativizarlos (...), muy por el contrario, para poner de manifiesto (...) lo que resulta del enfrentamiento de visiones del mundo diferente o antagónicas” (Bourdieu, 1999, p. 9).

Más allá de los diversos significados otorgados a la escuela, subyace con ímpetu la confianza en la escuela ligadas a las hipótesis de futuro. Los(as) estudiantes aluden a que "la escuela les sirve para después" (Dubet y Martuccelli, 1998) sea para conseguir un trabajo o seguir estudiando. En este sentido manifiestan seguridades presentes a planificaciones y orientaciones dirigidas al futuro (Mutchinick, 2008).

\section{Discusión y algunas conclusiones}

Las experiencias emocionales que de los(as) estudiantes indígenas construyen en la escuela secundaria están atravesadas por sentimientos de inferiorización y vergüenza que se erigen como muros simbólicos (Kaplan, 2018) y separan entre un nosotros y un ellos. Pero también por sentimientos confianza que impregnan los vínculos y también las perspectivas a futuro que proyectan en y a partir de la escuela.

Sentirse parte de un grupo implica sentirse reconocido/a, mirado/a, valorado/a, respetado/a. Silva (2018) tipifica a estos modos de relación como un trato simétrico entre pares. En contraste, sentirse excluido, no reconocido e inferiorizado constituyen formas de relación asimétrica (Silva, 2018) que a través de enunciaciones y prácticas de discriminación recaen sobre el origen sociocultural, las adscripciones identitarias y el hexis corporal (Bourdieu, 1998) de los(as) jóvenes indígenas. Es decir, "las desigualdades de recursos materiales y culturales entre los(as) estudiantes conllevan la producción de sentimientos de exclusión” (Kaplan y Szapu, 2019, p. 9). Estos sentimientos de la vida escolar están ligados a relaciones de poder entre grupos. Aquellos/as que se perciben en un lugar de superioridad tienden a estigmatizar a los/as individuos y grupos que carecen de ese sentimiento. En consecuencia, quienes se sienten discriminados/as, estigmatizados/as tienden a asumir un lugar de inferioridad. Es en esta instancia que las relaciones de dominación cobran sentido, los(as) estudiantes atravesados por sentimientos de exclusión "se desacreditan como producto del descrédito del que han sido objeto (Kaplan, 2008, p. 1).

Kaplan (2018) argumenta que las emociones y sentimientos del ámbito escolar conforman una compleja red que se expresa con consistencias y contradicciones. Por su parte, Le Breton 
(2013) sostiene que "las afectividades nunca tienen un solo tono, a menudo es mixta, oscila de un matiz al otro" (p. 71). No obstante, advertir sobre los efectos simbólicos que producen determinados modos de sociabilidad escolar pueden ser el punto de partida para desnaturalizar relaciones de humillación, inferiorización y exclusión que, tras su aparente carácter lúdico (Di Napoli, 2019), contribuyen a la producción de imágenes y autoimágenes devaluadas (Mutchinick y Silva, 2013), para que de ese modo se pueda favorecer a la búsqueda de restitución subjetiva de los(as) estudiantes (Kaplan y Szapu, 2019). 


\section{Referencias}

Bourdieu, P. y Saint Martin, M. (1988). Las categorías del juicio profesoral. Revista Propuesta Educativa, 9 (19), 4-18.

Bourdieu, P. (1978). El racismo de la inteligencia. Cahiers Droitet liberté (Races, sociétés et aptitudes: apports et limites de la science), (382), 67-71.

Briones, C. (2004). Construcciones de aboriginalidad en Argentina. Société suisse des Américanistes / Schweizerische Amerikanisten-Gesellschaft (78), 73-90.

De Gualejac, V. (2008). Las fuentes de la vergüenza. Buenos: Marmol Izquierdo.

Di Napoli, P. (2019). La construcción de sentidos en torno a las violencias por parte de los estudiantes en sus interacciones cotidianas. Espacio abierto. Cuaderno venezolano de sociología, 28 (2), 35-57.

Dubet, F., y Martuccelli, D. (1998). En la escuela. Sociología de la experiencia escolar. Buenos Aires: Losada.

Elias, N. (1987). El proceso de la civilización. Investigaciones sociogenéticas y psicogenéticas. México: Fondo de Cultura Económica.

Elias, N. (2003). Ensayo acerca de las relaciones entre establecidos y forasteros. Revista Española de Investigaciones Sociológicas (104), 219-251.

Gallart, M. (1993). La integración de Métodos y la Metodología Cualitativa. Una reflexión desde la práctica de la investigación. En F. Forni (Ed.) Métodos Cualitativos II. La práctica de la investigación. Bueno Aires: Centro Editor de América Latina.

Goudsblom, J. (2008). La vergüenza como dolor social. En C.V. Kaplan (Ed.) La civilización en cuestión. Escritos inspirados en la obra de Norbert Elias (pp. 13-28). Bueno Aires: Miño y Dávila.

Kaplan, C. V. (2008). Talentos, dones e inteligencias: El fracaso escolar no es un destino. Buenos Aires: Colihue.

Kaplan, C.V. y Khotsch, L. (2017) La educación de las emociones. Una perspectiva desde Norbert Elias. Revista Latinoamericana de investigación crítica 8 (V), 119-134. 
Kaplan, C.V. y Mutchinick, A. (2016). La civilización de los afectos en los procesos educativos. En C.V. Kaplan y M. Sarat (Coomp.) Educación y procesos de civilización. Miradas desde la obra de Norbert Elias, (pp. 145-169). Buenos Aires: Miño y Dávila.

Kaplan, C.V. y Silva, V. (2018). Respeto y menosprecio. Dos sentimientos estructurantes de la autoestima educativa. En C. V. Kaplan (Edit.) Emociones, sentimientos y afectos. Las marcas subjetivas de la educación (pp. 221-241). Buenos Aires: Facultad de Filosofía y Letras de la Universidad de Buenos Aires.

Kaplan, C.V. y Szapu, E. (2019). Jóvenes y subjetividad negada: Apuntes para pensar la intervención socioeducativa sobre prácticas autolesivas y suicidio. Psicoperspectivas. Individuo y sociedad 18 (1), 1-11.

Kaplan, C.V. (2013). El miedo a morir joven. Meditaciones de los estudiantes sobre la condición humana. En C. V. Kaplan (Direc.) Culturas estudiantiles. Sociología de los vínculos en la escuela (pp. 45-67). Buenos Aires: Miño y Dávila.

Kaplan, C.V. (2016). El lenguaje es una piel. Género, violencia y procesos civilizatorios. En C.V. Kaplan (Edit.) Género es más que una palabra. Educar sin etiquetas, (pp. 203-211). Buenos Aires: Miño y Dávila.

Kaplan, C.V. (2018). La naturaleza afectiva del orden social. Una cuestión rezagada del campo de la Sociología de la Educación. Sudamérica. Revista de Ciencias Sociales (9), $117-$ 128.

Kessler, G. (2004). Trayectorias escolares de jóvenes que cometieron delitos contra la propiedad con uso de violencia. (Documento de Trabajo de la Escuela de Educación). (C. Wainerman, Ed.). Ciudad Autónoma de Buenos Aires, Argentina.

Le Breton, D. (2010). Antropología del cuerpo y la modernidad. Buenos Aires: Nueva Visión.

Le Breton, D. (2010). Rostros. Ensayo de antropología. Buenos Aires: Letra Viva.

Le Breton, D. (2013). Por una antropología de las emociones. Revista Latinoamericana de Estudios sobre Cuerpos, Emociones y Sociedad (10), 67-76.

Mutchinick, A. y Silva, V. (2013). Las relaciones de humillación y la construcción de la autoestima escolar. La mirada de los jóvenes estudiantes sobre los sentimientos de 
Educa UMCH. Revista sobre Educación y Sociedad, 2020, 1(16), 5-22.

https://doi.org/10.15366/Educa UMCH2019.17.3.001

superioridad e inferioridad. En C. V. Kaplan (Direc.) Culturas estudiantiles. Sociología de los vínculos en la escuela. (pp. 69-102). Buenos Aires: Miño y Dávila.

Paulín, H. (2013). Conflictos en la sociabilidad entre jóvenes. Un estudio psicosocial sobre las perspectivas de estudiantes y educadores de escuelas secundarias. Universidad Nacional de Córdoba, Facultad de Psicología.

Piovani, J. I. (2007). La observación. En A. Marradi; A. Archenti, y J. I, Piovani (Edit) Metodología de las Ciencias Sociales. (pp. 191-201). Buenos Aires: Emecé.

Silva, V. (2018). La construcción social del respeto en la escuela. Un estudio socioeducativo desde la perspectiva de las y los jóvenes estudiantes. (Tesis de doctorado) Universidad Nacional de la Plata. Recuperado de

\section{http://www.memoria.fahce.unlp.edu.ar/tesis/te.1630/te.1630.pdf}

Simmel, G. (2003). Cuestiones fundamentales de sociología. Barcelona: Gedisa.

Valles, M. (1999). Técnicas cualitativas de Investigación social. Reflexión metodológica y práctica profesional. Reflexión Metodológica y Práctica Profesional. Madrid: Síntesis. http://doi.org/8477384495. 